\title{
Effect of the conduit material on CICC performance under high cycling loads
}

N. N. Martovetsky, P. Bruzzone, B. Stepanov, R. Wesche, C. Gung, J. V. Minervini, M. Takayasu, L. F. Goodrich, J. W. Ekin, A. Nijhuis

September 2, 2004

Applied Superconductivity Conference Jacksonville, FL, United States October 3, 2004 through October 8, 2004 
This document was prepared as an account of work sponsored by an agency of the United States Government. Neither the United States Government nor the University of California nor any of their employees, makes any warranty, express or implied, or assumes any legal liability or responsibility for the accuracy, completeness, or usefulness of any information, apparatus, product, or process disclosed, or represents that its use would not infringe privately owned rights. Reference herein to any specific commercial product, process, or service by trade name, trademark, manufacturer, or otherwise, does not necessarily constitute or imply its endorsement, recommendation, or favoring by the United States Government or the University of California. The views and opinions of authors expressed herein do not necessarily state or reflect those of the United States Government or the University of California, and shall not be used for advertising or product endorsement purposes. 


\title{
Effect of the conduit material on CICC performance under high cycling loads
}

\author{
Nicolai N. Martovetsky, Pierluigi Bruzzone, Boris Stepanov, Rainer Wesche, Chen-yu Gung, \\ Joseph V. Minervini, Makoto Takayasu, Loren F. Goodrich, Jack W. Ekin, Arend Nijhuis
}

\begin{abstract}
Recent ITER Model Coils and CRPP tests on Nb3Sn Cable in Conduit Conductors (CICC) showed a significant and unexpected increase in the broadness of the transition to the normal state, resulting in degradation of superconducting properties. To investigate these phenomena two CICC samples were built with identical 144 strand cables but different conduit materials. One sample had titanium conduit with low coefficient of thermal expansion (CTE), the other had stainless steel conduit. The purpose of this experiment was to study changes in strand properties in the cable (n-value, $I_{c}, T_{c s}$ ), the effect of cycling and high electromagnetic load and the effect of the conduit on the CICC performance.
\end{abstract}

Index Terms-Superconducting cables, superconducting filaments and wires, Nb3Sn cable in conduit.

\section{INTRODUCTION}

It is well known that the Nb3Sn critical current is sensitive to strain and therefore to the conduit material CTE. Degradation of the superconducting properties observed in ITER Model Coils test results [1-3] extended our knowledge base about $\mathrm{Nb}_{3} \mathrm{Sn} \mathrm{CICC}$ and required significant conductor design changes in order to meet ITER requirements. Many questions about $\mathrm{Nb}_{3} \mathrm{Sn}$ CICC behavior with high currents still remain without satisfactory explanation. In the Model Coils it was observed that all tested $\mathrm{Nb}_{3} \mathrm{Sn}$ CICC performed below expectations as estimated by the mismatch between coefficients of thermal expansion (CTE) for the conduit and the strands. Especially surprising was lower than expected

Manuscript received October 5, 2004. This Work supported by, the US Department of Energy under contract to the Lawrence Livermore National Laboratory (contract No. W-7405-Eng-48), under MIT Grant No. DEFC02-93ER54186-D\&T and by European Fusion Technology Program.

Author N.M. is with Lawrence Livermore National Laboratory, Livermore, CA 94550 USA (telephone: (925) 422 4269, e-mail: martovetsky1@1lnl.gov)

P.B., B.S., R.W. are with the Centre de Recherches en Physique des Plasmas, CH-5232 Villigen-PSI, Switzerland (e-mail: pierluigi.bruzzone@psi.ch)

C.G., J.V.M. and M.T. are with MIT Plasma Science and Fusion Center, Cambridge MA 02139, USA (e-mail: minervini@psfc.mit.edu)

L.F.G. and J.W.E. are with the National Institute of Standards and Technology, Boulder, CO, 80305 USA (e-mail: goodrich@boulder.nist.gov)

A.N. is with University of Twente 7500 AE Enschede, the Netherlands (e-mail: a.nijhuis@tn.utwente.nl)

Contribution of the NIST, not subject to copyright. Certain commercial materials are referred to in this paper to foster understanding. Such identification does not imply recommendation or endorsement by the NIST, nor does it imply that the materials identified are necessarily the best available for the purpose. performance of the CICC in low CTE conduits (Incoloy and Ti), which were expected not to degrade the superconducting cable noticeably. The TFMC [3], the only stainless steel (SS) CICC in this R\&D, also showed somewhat more degradation than expected.

Model Coils also showed that cyclic loads could cause yet more degradation of properties. One low CTE CICC had significant degradation (about $0.5 \mathrm{~K}$ ) [1], and another one about $0.15 \mathrm{~K}$ [4]. The remaining low CTE [2] and SS CICC [3] had cyclic degradation less than barely detectable $0.1 \mathrm{~K}$.

The CICC design and analysis in ITER and many other projects are based on the correlation of $\mathrm{Nb}_{3} \mathrm{Sn}$ performance by Summers-Ekin [5] based on strain data above $-(0.3-0.4 \%)$ and extrapolated to higher compressive strain when necessary. The data obtained recently by University of Durham group [6] on $\mathrm{Nb}_{3} \mathrm{Sn}$ strands under higher uniaxial compression suggest that the Summers relation is too optimistic for highly compressed $\mathrm{Nb}_{3} \mathrm{Sn}$. This now introduces confusion about prediction of the CICC properties on the basis of the strand properties, since the Durham correlation has a narrow range of validity and Summers correlation was used for the analysis and interpretation of the CSMC and most $\mathrm{Nb}_{3} \mathrm{Sn}$ conductors since 1991, including highly compressed CICC with SS conduits.

The Model Coil data had limited accuracy since there was noticeable scatter in the properties of the strands used. Also, due to a very large magnet and difficult access, it was not always possible to place the instrumentation in the best locations. Also it was not possible to know if handling the conductor during fabrication after the heat treatment (HT) caused any degradation.

The objective of the experiment discussed in this paper was to study the transformation of the Nb3Sn strand properties in CICC based on accurate knowledge of the initial strand properties and to compare behavior of CICC in steel and low CTE conduits undisturbed by coil fabrication operations after HT. Two identical cables made from the excess IGC strand used for the CS Model Coil were encapsulated into two tubes: 304 type stainless steel and pure Ti conduits. We bent the CICC into hairpin samples and heat-treated them. We instrumented the samples with voltage taps and temperature sensors and tested the samples in fields up to $11 \mathrm{~T}$ in the SULTAN facility at CRPP, Switzerland. To eliminate the current redistribution problems, the cable terminations were stripped of $\mathrm{Cr}$ plating and filled with $\mathrm{SnAg}$ solder. The conductors layout is given in Table I. 
TABLE I

TESTED CICC PARAMETERS

\begin{tabular}{|c|c|c|}
\hline & $\mathrm{SS}$ & $\mathrm{TI}$ \\
\hline $\begin{array}{c}\mathrm{Nb}_{3} \mathrm{Sn} \text { strand } \\
\text { Diameter }\end{array}$ & \multicolumn{2}{|c|}{$0.81 \mathrm{~mm}$} \\
\hline $\mathrm{Cu}$ :non- $\mathrm{Cu}$ & \multicolumn{2}{|c|}{$1.5 \pm 0.05$} \\
\hline Cr plating & \multicolumn{2}{|c|}{$2 \mu \mathrm{m}$} \\
\hline Cable configuration & \multicolumn{2}{|c|}{$3 \times 3 \times 4 \times 4=144$} \\
\hline Cable pitches & \multicolumn{2}{|c|}{$10 / 51 / 79 / 136 / 166 \mathrm{~mm}$ right hand } \\
\hline Void fraction & \multicolumn{2}{|c|}{$\approx 33.1 \%$} \\
\hline CICC diameter, $\mathrm{mm}$ & $14.51-14.57$ & $14.56-14.59$ \\
\hline Jacket material & $\begin{array}{l}\text { Stainless steel } \\
12 \mathrm{X} 18 \mathrm{H} 110 \mathrm{~T}\end{array}$ & Ti (grade 2) \\
\hline
\end{tabular}

\section{STRAND CHARACTERIZATION}

The strand properties were measured in several laboratories: NIST, MIT, CRPP and University of Twente (UT). UT measured strain effect at two temperatures, work is still in progress, the NIST and CRPP had variable temperature capability, while all MIT data were taken at $4.2 \mathrm{~K}$. The scatter among the NIST, UT and CRPP data without applied strain was small; MIT data were $2-3 \%$ lower. The strand properties without applied strand can be satisfactory described by the Summers correlation [5] with the following parameters: $\mathrm{Co}=11776 \mathrm{AT} / \mathrm{mm}^{2}, \mathrm{~T}_{\mathrm{c} 0 \mathrm{~m}}=16.8 \mathrm{~K}, \mathrm{~B}_{\mathrm{c} 2 \mathrm{~m}}=28.5 \mathrm{~T}$, assuming resulting stress of $-0.25 \%$. The strain sensitivity was measured at NIST on an identical strand which underwent slightly different heat treatment resulting in $11 \%$ higher $\mathrm{I}_{\mathrm{c}}(12$ $\mathrm{T}, 4.2 \mathrm{~K}, 10 \square \mathrm{V} / \mathrm{m}$ ). Reduced by $11 \% \mathrm{I}_{\mathrm{c}}$ data are showed in Fig. 1 along with the Summers correlation.

\section{CICC WITH SS CONDUIT}

The test procedure for the samples was as follows.

After calibration runs and checks and $\mathrm{AC}$ tests with no transport current, the $\mathrm{Tc} 0 \mathrm{~m}$ measurements were attempted but were not very successful due to hydraulic instabilities above $15 \mathrm{~K}$. The $\mathrm{I}_{\mathrm{c}}$ was then measured in the background field. We started at the lowest IxB force at $11 \mathrm{~T}$ and $8 \mathrm{~K}$ to find out if first cycle of electromagnetic loading is important in the degradation evolution. The critical current $I_{c}$ and current

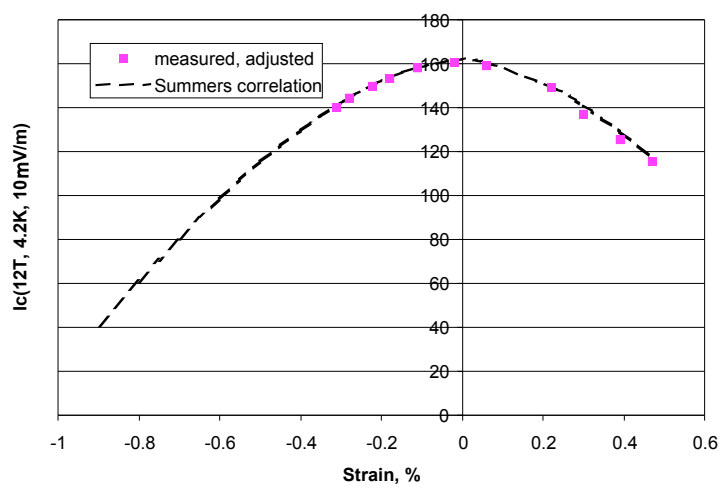

Fig. 1. Strain sensitivity of the IGC strand at $12 \mathrm{~T}$ and $4.2 \mathrm{~K}$.

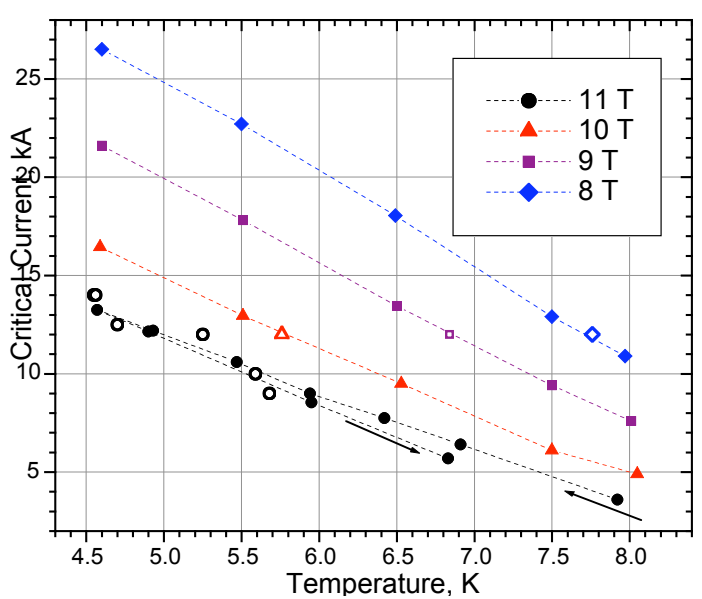

Fig. 2. $\mathrm{I}_{\mathrm{c}}$ (solid) and $\mathrm{T}_{\mathrm{cs}}$ (open symbols) of CICC SS before cycles.

sharing temperature $T_{c s}$ were measured at $10 \square \mathrm{V} / \mathrm{m}$ over $30 \mathrm{~cm}$ in the high field length. All data are taken at $3 \mathrm{~g} / \mathrm{s}$ flow rate through each leg. Test results on the SS sample before cycling are shown in Fig.2. The arrows for $11 \mathrm{~T}$ measurements indicate the sequence of $I_{c}$ measurements. It is seen that after exposing the CICC to the highest $\mathrm{IxB}$ the $\mathrm{I}_{c}$ noticeably decreased, which shows that the very first loading affects the strand properties.

After cycling from 0 to $17 \mathrm{kA}$ at $10 \mathrm{~T}$ and $4.5 \mathrm{~K}$, the properties of the CICC degraded in a more continuous manner. The $\mathrm{I}_{\mathrm{c}}$ of the SS sample came to saturation after about 600 cycles as shown in Fig. 3. The nomenclature b.c. corresponds to "before cycles" and a.c. to "after cycles". The $\mathrm{I}_{\mathrm{c}}$ dropped by $10-20 \%$ (higher in higher field) and in terms of $\mathrm{T}_{\mathrm{cs}}$ - by about $0.5 \mathrm{~K}$ at $11 \mathrm{~T}$-about the same amount as the ITER CS Insert and with a similar amount of cycles to saturation. Similar to this work, samples measured at SULTAN in the year 2001 [8] had the $I_{c}$ saturated after about 2500 cycles, but the $\mathrm{I}_{\mathrm{c}}$ degradation was about $20 \%$ there.

\section{CICC WITH TI CONDUIT}

The CICC with Ti conduit tests were conducted similar to the CICC with SS conduit. The Ti conduit sample had higher initial $I_{c}$ and $I_{q}$, as expected. The degradation of current as a result of cycling was similar to the SS CICC.

Fig. 4 shows comparative degradation of the CICCs

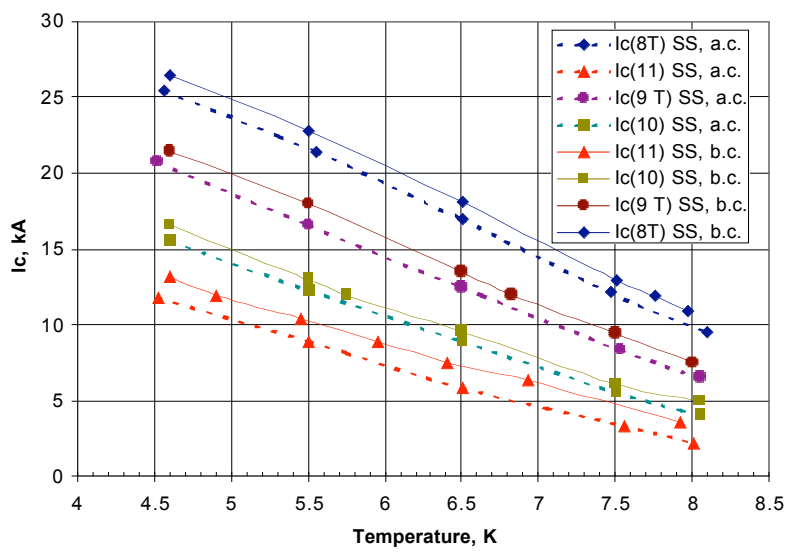

Fig. 3. Ic $(10 \square \mathrm{V} / \mathrm{m})$ in the SS CICC before and after cycles. 


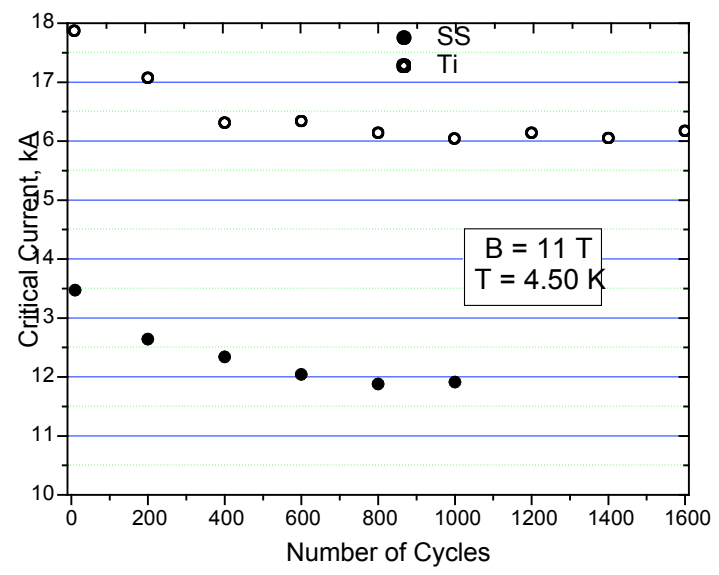

Fig. 4. Evolution of Ic as a result of load cycles

studied. The ratio between $\mathrm{I}_{\mathrm{c}}(\mathrm{Ti})$ and $\mathrm{I}_{\mathrm{c}}(\mathrm{SS})$ versus cycles at $11 \mathrm{~T}$ and $4.5 \mathrm{~K}$ always was in the range of 1.32-1.36.

In agreement with earlier results reported in [8], the quench current $I_{q}$ (thermal run away) changed much less than $I_{c}$ due to cycles. Fig. 5 shows comparison of $I_{q}$ for both CICCs. The quench current depends on the helium mass flow and length of the conductor in the peak field [9], therefore it reflects not only the superconducting properties, like $\mathrm{I}_{\mathrm{c}}$, but also operating conditions. Both $\mathrm{I}_{\mathrm{c}}$ and $\mathrm{I}_{\mathrm{q}}$ of the low CTE Ti conduit show about $30 \%$ advantage over the SS conduit at $11 \mathrm{~T}$ and $4.5 \mathrm{~K}$. At $12 \mathrm{kA}$ and $11 \mathrm{~T}$ the Ti CICC has Tes by $1.3 \mathrm{~K}$ higher than the SS CICC. This result is consistent with the ITER Model Coil results [4] where similar performance strands (Furukawa and LMI) had about 25-30\% advantage in Incoloy 908 conduit (CS Insert) versus SS conduit and structure (TFMC). The advantage is lower than the expected $50-60 \%$ before Model Coil program.

Such a small difference in $I_{q}$ at noticeable reduction of $I_{c}$ as a result of the cyclic load can be explained by a reduction of the $\mathrm{n}$-value of the resistive transition, expressed as $\mathrm{E}=\left(10^{-5}\right) *(\mathrm{I} /$ $\left.I_{c}\right)^{n}[V / m]$, where $I_{c}$ is defined at the level of $10^{-5} \mathrm{~V} / \mathrm{m}$.

Fig. 6 shows a summary of the n-value for the original strands

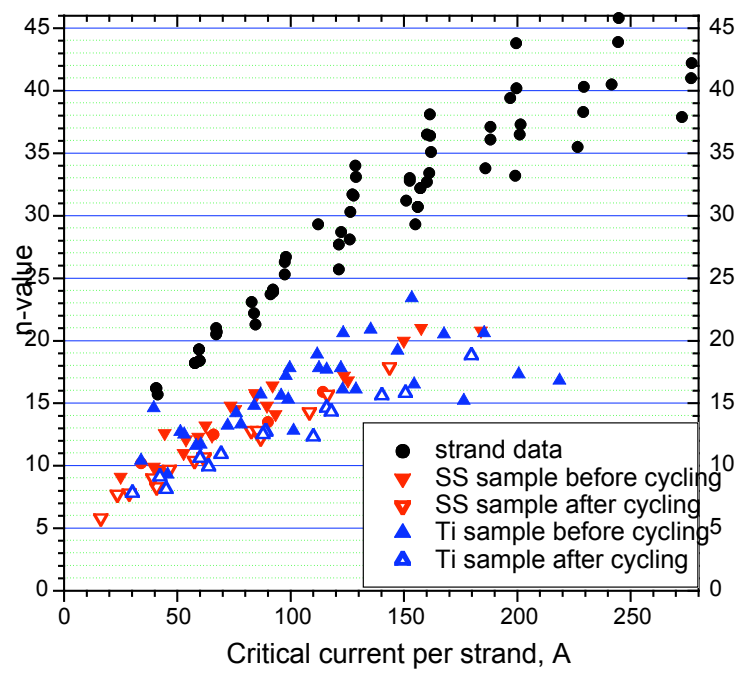

Fig. 6. Summary of the n-value measurements

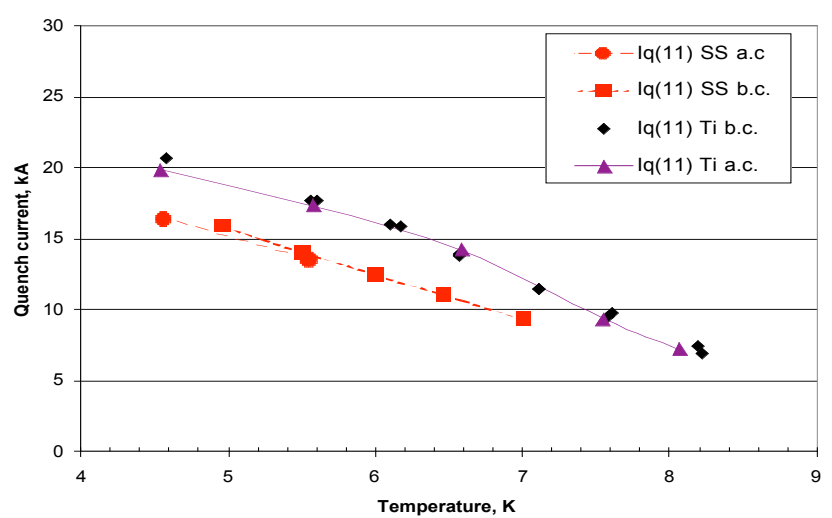

Fig. 5. Quench current in CICC at $11 \mathrm{~T}$ before and after the cycles. The lines are to guide the eye.

and for both CICCs. As in the ITER Model Coils, the n-value for CICC is significantly lower than that in the stand-alone strand, including the data before loading and at minimal $\mathrm{IxB}$ values. That suggests that the degradation in the strands at least partially comes from heat treatment in a conduit and following cooldown. Quantitatively, the n-value for low CTE conduits tested at Model Coils (about 8 at $40 \mathrm{~A} /$ strand) [1] is similar to values observed in our tests, while the n-value measured in the TFMC (about 7 at $111 \mathrm{~A} /$ strand) is significantly lower than what we measured for SS CICC. It is unexpected to see that the low CTE conduit did not produce higher $\mathrm{n}$-values in the cable than in the SS conduit. Strand data $[6,7]$ on $I_{c}$ versus strain always showed a higher $I_{c}$ associated with a higher n-value.

\section{Post TEST ANALYSIS AND DISCUSSION}

We assume that the current is uniformly distributed over the cable, which is confirmed by negligible voltage measured across the cross section. Thus, the CICC transition represents purely strand behavior, not current transfer between the strands. To compare performance of the strand with CICC, we need to take into account that the strand in CICC is located in a variable field due to self-fields produced by the transport current and cabling. We used a double spiral to model the four-stage cable, modeling only the two most important last cabling stages, and calculated the electrical field along the length of the strand. The integrated electrical field should be compared to the measured electrical field. For the sake of analysis, the varying magnetic field along the length of the strand between the voltage taps is replaced with a single value of the "effective magnetic field", which is found to fit the integrated electrical field along the strand. This effective magnetic field, Beff, depends on the n-value. For an n-value of 10 , Beff is approximately equal to the median magnetic field between the peak and average in the cable cross section. That is $\mathrm{Beff}=($ Bpeak + Baverage $) / 2=$ Bsultan $+\mathrm{kI}$, where coefficient $\mathrm{k}$ is computed to be $0.02 \mathrm{~T} / \mathrm{kA}$ and $\mathrm{I}$ is the transport current. At the highest transport currents of $30 \mathrm{kA}$, the effective magnetic self-field is calculated as $0.6 \mathrm{~T}$ and peak electrical field is about 4 times higher than the measured average electrical field.

The anticipated strain of the Nb3Sn strands in the SS 
TABLE II

FITTING PARAMETERS FOR THE STRAIN IN CICC

conduits after cooldown is somewhere within $-0.55-0.75 \%$. For the Ti CICC we anticipated about $-0.2-0.3 \%$.

Although there are doubts that the Summers correlation is accurate for high compressive strains, we will assess the CICC performance using the Summers correlation in the full range of the strain, since we do not have reliable data and correlation for high compressive strain yet. This approach may mean that the strain deduced from the test data may be merely a fitting parameter rather than a real strain in the strands. But even such reservation makes analysis valuable for comparison with the Model Coils results. Also, the model can be used for CICC design if operating conditions are not far away from the test conditions.

In the Model Coil analysis, the Summers correlation was used to compare the performance of the strand in CICC and stand-alone strand. It was found $[3,10]$ that this correlation can describe the parameters of the CICC if a fitting parameter is introduced in the form of an extra strain in addition to cool down and operating hoop strain (hoop strain is zero in our test): $\square=\square_{c d}+\square_{o p}+\square_{\text {extra }}$. This additional strain is assumed as $\square_{x t r a}=a I B$ that takes into account the transverse force crushing and bending the strands in the cable in lateral direction; this is just a common sense speculation. Using this approach we found the best fit to describe the test data and results by the Summers correlation.

The fitting process results are given in Table II in terms of cooldown strain and coefficient for the extra strain. Some analysis data from the Model Coil program are shown for comparison, which indicate that a low CTE conduit is a superior material for Nb3Sn CICC to the SS. The advantage, however, is less than expected from $I_{c}$ versus uniaxial strain data.

\section{CONCLUSION}

Low CTE conduit maintains its significant advantage in $\mathrm{I}_{\mathrm{c}}$ and $\mathrm{I}_{\mathrm{q}}$ over the SS conduit in all tested conditions. Both CICCs experience about $10 \%$ degradation in $I_{c}$ due to cycling, suggesting that the effect of cycling on $I_{c}$ is insensitive to the conduit material.

Even with careful handling after heat treatment, the degradation in $\mathrm{I}_{\mathrm{c}}$ for the CICC with low CTE is comparable to the degradation seen in CSMC, CS and TF inserts. We see degradation even before high electromagnetic loads are applied. Thus, low CTE conduits do not completely eliminate $\mathrm{I}_{\mathrm{c}}$ degradation and that suggests that the CICCs in Model Coil program were not damaged during fabrication.

The n-value in the low CTE conduit CICC is only slightly higher than in the SS conduit; both are a little more than one half that of the original strand, which is unexpected and yet to be explained.

The subscale tests reproduced many Model Coil program results and gave valuable data for CICC design database.

\begin{tabular}{lll}
\hline & $\square c d^{\%}$ & $a[1 / \square \square \square]$ \\
\hline Ti CICC b.c. & -0.458 & $-4.20 \mathrm{e}-6$ \\
\hline Ti CICC a.c. & -0.539 & $-2.65 \mathrm{e}-6$ \\
\hline SS CICC b.c & -0.600 & $-6.91 \mathrm{e}-6$ \\
\hline SS CICC a.c. & -0.683 & $-3.75 \mathrm{e}-6$ \\
\hline Ti TFI in SS structure [11] & -0.575 & $-2.58 \mathrm{e}-6$ \\
\hline SS TFMC [3,10] & -0.66 & $-2.3 \mathrm{e}-6$ \\
\hline Incoloy CSI [10] b.c. & -0.32 & $-3.5 \mathrm{e}-6$ \\
\hline Incoloy CSI b.c. [12] & -0.45 & $\mathrm{n} / \mathrm{a}$ \\
\hline Incoloy CSI a.c. [12] & -0.56 & $\mathrm{n} / \mathrm{a}$ \\
\hline
\end{tabular}

\section{ACKNOWLEDGMENT}

We are grateful to V.E. Sytnikov and VNIIKP group for fabrication of the CICCs and CRPP personnel for preparation and running the test.

\section{REFERENCES}

[1] N. Martovetsky, P. Michael, J. Minervini et al, "ITER CS Model Coil and CS Insert test results" IEEE Trans. Applied Superconductivity, vol. 11, N1, p. 2030, March 2001

[2] N. Martovetsky, M. Takayasu, et al, "Test of the ITER TF Insert and Central Solenoid Model Coil", IEEE Trans. Applied Superconductivity, Volume: 13, Issue: 2, June 2003,p.1441

[3] R. Zanino, M. Bagnasco, G. Dittrich, et al., "T $T_{\text {cs }}$ tests and performance assessment of the ITER Toroidal Field Model Coil (Phase II)", IEEE Trans. Applied Superconductivity, vol. 14, no. 2, June 2004, pp.1519.

[4] N. Martovetsky, M. Takayasu, et al, "Test of the NbAl Insert and ITER Central Solenoid Model Coil", IEEE Trans. Applied Superconductivity, Volume: 13, Issue: 2, June 2003,p.1437.

[5] L. T. Summers, M. Guinan et al, A Model for the Prediction of Nb3Sn Critical Current as a Function of Field, Temperature and Radiation Damage, IEEE Trans on Magnetics, 27(2), March 1991, 2041.

[6] Keyes, S.A. and Hampshire, D.P., 'A scaling law for the critical current density of weakly- and strongly-coupled superconductors, used to parameterize data from a technological $\mathrm{Nb} 3 \mathrm{Sn}$ strand', Superconductor Science and Technology, Vol. 16, (2003), 1097.

[7] A.Godeke, H.G. Knoopers, A. Nijhuis, H.J.G. Krooshoop, B. ten Haken and H.H.J. ten Kate, Characterisation of ITER strands in the frame of the third benchmark tests, Report UT-NET 98-5, April 1998

[8] P. Bruzzone, A. Fuchs, B. Stepanov, G. Vecsey, "Performance Evolution of Nb3Sn Cable-in-conduit conductors under cyclic load", IEEE Trans. Applied Superconductivity, v. 12, No.1, March 2002, p.516.

[9] N. Martovetsky, "Stability and thermal equilibrium in cable-in-conduit conductors, Physica C: Superconductivity, Volume 401, Issues 1-4, 2004, p. 118.

[10] N. Mitchell, "Summary, assessment and implications of the ITER model coils test results", Fusion Engineering and Design, v. 66-68, 2003, p. 971.

[11] D. Bessette, "Modeling Techniques for Correcting Measured Data on the ITER Toroidal Field Insert Coil", IEEE Trans. Applied Superconductivity, vol. 14, no. 2, June 2004, p.1418.

[12] N. Martovetsky, " $T_{c s}$ and $I_{c}$ measurements in CSMC", presented at JAERI meeting on CSMC Test results, Naka, Nov. 2000, unpublished. 